Steven E. Kern PhD, *

Robert J. Fragen MD, $†$

Paul C. Fitzgerald BSN MS, $\uparrow$

Michiel van Zeeland DRMED, *

Joel O. Johnson MD PhD, ${ }^{\star} \ddagger$

\title{
Impact of the initial doses of rocuronium and pancuronium on subsequent maintenance for neuromuscular block
}

Purpose: To determine the impact of the neuromuscular blocking agent given for intubation on the duration of effect of multiple maintenance doses of pancuronium and rocuronium.

Methods: Seventy-eight subjects were randomly assigned to receive one of four dosing combinations for intubation and neuromuscular maintenance: rocuronium for intubation and maintenance, rocuronium for intubation and pancuronium for maintenance, pancuronium for intubation and rocuronium for maintenance, or pancuronium for both. Each time that the first twitch response returned to $25 \%$ of the baseline value, the duration of the dose was determined and another maintenance dose was administered. The duration of action of the maintenance doses was compared between the groups.

Results: Twitch suppression from the first maintenance dose was shorter for subjects who received rocuronium for both doses (Group RR) compared with that for subjects that received pancuronium (Groups PR \& PP) as their intubation dose ( 17.6 vs $34 \& 59.8$ min, respectively, $P<0.05$ ). Subjects who received rocuronium followed by pancuronium (Group RP) showed a shorter duration of twitch suppression after the first maintenance dose than the group that received pancuronium for both doses (Group PP) (21.3 vs $59.8 \mathrm{~min}, P<0.05$ ). By the third maintenance dose, the influence of the intubating dose on the maintenance dose duration had essentially diminished.

Conclusions: For combinations of rocuronium and pancuronium, the duration of twitch suppression after a maintenance dose is only dependent on the first agent given for the first two maintenance doses administered.

Objectif : Déterminer l'impact d'un myorelaxant, administré pour l'intubation, sur la durée de l'effet de multiples doses d'entretien de pancuronium et de rocuronium.

Méthode : Soixante-dix-huit sujets, répartis de façon aléatoire en quatre groupes, ont reçu l'une des quatre combinaisons suivantes de médicaments pour l'intubation et le maintien du bloc neuromusculaire : du rocuronium pour les deux, du rocuronium pour l'intubation et du pancuronium pour le maintien, du pancuronium pour l'intubation et du rocuronium pour le maintien ou du pancuronium pour les deux. Chaque fois qu'une première réponse à la stimulation affichait une valeur équivalente à $25 \%$ de la valeur de base, la durée de la dose était déterminée et une autre dose de maintien administrée. On a comparé le temps d'action des doses de maintien pour les quatre groupes.

Résultats : La suppression de la réaction à la première dose de maintien a été plus courte chez les sujets qui ont reçu du rocuronium pour les deux doses (groupe RR) comparés à ceux qui ont reçu du pancuronium (groupes PR et PP) pour l'intubation ( I7,6 vs 34 et 59,8 min, respectivement, $P<0,05$ ). Chez les sujets qui ont reçu du rocuronium, puis du pancuronium (groupe RP), la suppression de la réaction a été de plus courte durée après la première dose de maintien que chez les sujets qui ont reçu du pancuronium pour les deux doses (groupe PP) (2l,3 vs 59,8 min, $P<0,05)$. À la troisième dose de maintien, l'influence de la dose d'intubation sur la durée de la dose de maintien avait essentiellement diminué.

Conclusion : Dans le cas d'une combinaison de rocuronium et de pancuronium, la durée de la suppression de la réponse à un stimulus qui suit l'administration d'une dose de maintien dépend seulement du premier médicament donné pour les deux premières doses de maintien.

From the Departments of Anesthesiology, University of Utah School of Medicine, * Salt Lake City, Utah, Northwestern University Medical School, † Chicago, Illinois and University of Missouri Hospital \& Clinics, $\ddagger$ Columbia, Missouri, USA.

Address correspondence to: Dr. S.E. Kern, Department of Anesthesiology, University of Utah School of Medicine, University of Utah School of Medicine, ${ }^{*} 50$ N. Medical Drive, Salt Lake City, Utah 84132 USA. E-mail: skern@remi.med.utah.edu Study funded in part by Organon, Inc. West Orange, NJ 07052.

Presented in part at the annual meeting of the American Society of Anesthesiologists, Dallas, Texas, October 1999.

Accepted for publication October 8, 2000.

CAN J ANESTH 2001/48:2/pp 129-132 
$\mathrm{T}$ HE ideal neuromuscular blocking agent should have a rapid onset and a predictable duration of action, even after several maintenance doses, to avoid postoperative residual neuromuscular block. No single drug currently meets these characteristics. Several investigators have tried to combine neuromuscular blocking agents, making use of their pharmacokinetic differences and pharmacological interactions, to improve the pharmacodynamic profile for these agents. ${ }^{1-4}$

The aim of this study was to compare the clinical duration of pancuronium and rocuronium maintenance doses following an intubation dose of either agent. We were interested in determining the impact of the intubating dose agent on maintenance dose duration and accumulation when the short acting rocuronium and the long acting pancuronium are combined.

Methods

The study was an open-label, randomized comparison of clinical recovery time in four dosing groups. Patients scheduled for elective surgery expected to last two hours or longer were recruited. After Institutional Review Board approval, subjects, 18 - 65 yr, ASA class 1-3, non-pregnant if female, without history of renal, hepatic, or neuromuscular disorders, and not receiving chronic antihistamines, anticonvulsants, or aminoglycoside antibiotics consented to participate.

Subjects were randomized into one of four groups: rocuronium for onset and maintenance of relaxation (Group RR), rocuronium for onset and pancuronium for maintenance (Group RP), pancuronium for onset and rocuronium for maintenance (Group PR), or pancuronium for onset and maintenance (Group PP). The intubation dose for groups RR and RP was 600 $\mu \mathrm{g} \cdot \mathrm{kg}^{-1}$ rocuronium and for groups $\mathrm{PR}$ and $\mathrm{PP}, 100$ $\mu \mathrm{g} \cdot \mathrm{kg}^{-1}$ pancuronium. The maintenance dose for subjects receiving rocuronium (groups RR and PR) was $150 \mu \mathrm{g} \cdot \mathrm{kg}^{-1}$ and $25 \mu \mathrm{g} \cdot \mathrm{kg}^{-1}$ for subjects receiving pancuronium (groups RP and PP).

Subjects were premedicated with midazolam (1-2 $\mathrm{mg}$ ) and anesthesia was induced and maintained with an infusion of propofol (1-2 $\mathrm{mg} \cdot \mathrm{kg}^{-1}$ induction, 100$200 \mu \mathrm{g} \cdot \mathrm{kg}^{-1} \cdot \mathrm{min}^{-1}$ maintenance) supplemented with intermittent doses of fentanyl (100-250 $\mu \mathrm{g})$. Subjects also received $\mathrm{N}_{2} \mathrm{O} 66 \%$ by inhalation. Muscle twitch was evoked by stimulation of the ulnar nerve with train of four (TOF) supramaximal square wave impulses every $10 \mathrm{sec}$. Within two minutes before induction of muscle relaxation, single twitch stimuli $(0.2 \mathrm{msec}$ duration) at a frequency of $0.1 \mathrm{~Hz}$ were administered to determine baseline control values for the evoked force response.
TABLE Median duration times and their range (25\%-75\%) for three maintenance doses administered in the study.

\begin{tabular}{|c|c|c|c|c|}
\hline $\begin{array}{l}\text { Maintenance } \\
\text { Dose }\end{array}$ & Group RR & Group RP & Group PR & Group PP \\
\hline Dose 1 duration & $17.6 \min ^{*} \dagger$ & $21.3 \min \ddagger$ & $34 \min \dagger$ & 59.8 min* $\ddagger$ \\
\hline $25 \%-75 \%$ range & $14.0-22.9$ & $19.3-28.6$ & $630.4-38.4$ & $43.4-70.1$ \\
\hline$(\mathrm{n})$ & $(20)$ & $(20)$ & $(18)$ & $(17)$ \\
\hline Dose 2 duration & $19.2 \min ^{*} \dagger$ & $38.3 \min \dagger$ & $29.5 \mathrm{~min} \ddagger$ & $57.1 \min ^{*} \ddagger$ \\
\hline $25 \%-75 \%$ range & $15.1-23.8$ & $30.6-47.3$ & $27.3-37.3$ & $43.3-69.8$ \\
\hline (n) & $(20)$ & $(20)$ & $(14)$ & (12) \\
\hline Dose 3 duration & $20.5 \min ^{*} \dagger$ & $44.1 \mathrm{~min} \dagger$ & $26.6 \mathrm{~min}$ & $55.5 \mathrm{~min}^{*}$ \\
\hline $25 \%-75 \%$ range & $16.1-24.6$ & $41.9-55.9$ & $24.3-42.4$ & $48.9-72.6$ \\
\hline$(\mathrm{n})$ & $(20)$ & (14) & $(7)$ & $(9)$ \\
\hline
\end{tabular}

Dose 1 : ${ }^{*} \mathrm{RR}<\mathrm{PP}, \dagger \mathrm{RR}<\mathrm{PR}, \ddagger \mathrm{RP}<\mathrm{PP} P<0.05$

Dose $2:{ }^{*} \mathrm{RR}<\mathrm{PP}, \dagger \mathrm{RR}<\mathrm{RP}, \ddagger \mathrm{PR}<\mathrm{PP} P<0.05$

Dose 3: ${ }^{*} \mathrm{RR}<\mathrm{PP}, \dagger \mathrm{RR}<\mathrm{RP} P<0.05$

The resulting contraction force of the adductor pollicis was measured with mechanomyography.

Each time the response to the first twitch in the train-of-four had returned to $25 \%$ of baseline, the time was noted and a maintenance dose of relaxant was given. After recovery of $\mathrm{Tl}$ to $25 \%$ from the last maintenance dose, muscle relaxation could be reversed with neostigmine and glycopyrrolate if the anesthesiologist felt it was clinically necessary. The temperature at the adductor pollicis surface was measured and kept $\geq$ $32^{\circ} \mathrm{C}$. $^{5}$

The duration of action of the maintenance doses was compared among groups using Kruskal-Wallis one way analysis of variance based on ranks. Dunn's method was used to correct for multiple comparisons. In all analyses, a $P \leq 0.05$ was considered significant.

Results

Ninety-six subjects were enrolled. Of these, 18 failed to reach $25 \%$ recovery of one maintenance dose before the end of surgery and were excluded from analysis. The remaining 78 subjects showed no difference among the patient groups with respect to age or weight.

Of the 78 subjects analyzed, 50 received three maintenance doses during surgery. The duration of the first maintenance dose was shorter for subjects who received rocuronium for both doses (Group RR) than in the two groups that received pancuronium as their intubation dose (Groups PR, PP). The maintenance dose duration for the group that received rocuronium followed by pancuronium (Group RP) was shorter than that in the group that received pancuronium for both doses (Group PP).

For the second maintenance dose, the duration of group RR was shorter than that for groups RP and PP, 


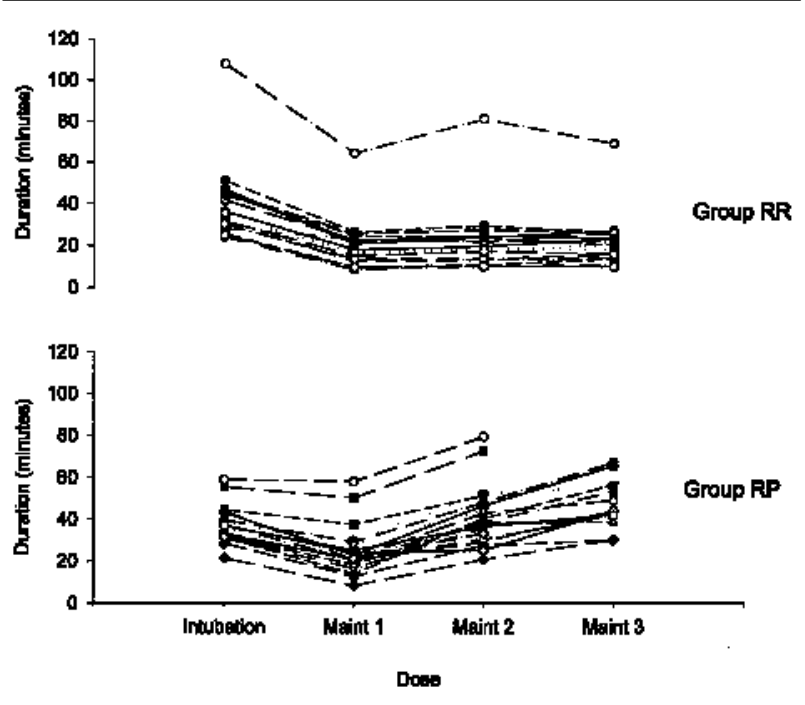

FIGURE IA Individual dose durations until recovery of Tl to $25 \%$ of baseline for each group of subjects in the study. Group RR received rocuronium for both intubation and maintenance. Group $\mathrm{RP}$ received rocuronium for intubation and pancuronium for maintenance.

but not for PR. The duration for group PR was also shorter than the duration for group PP. For the third maintenance dose, group RR was again shorter than group RP and group PP, but not for group PR (Table).

Discussion

For combinations of rocuronium and pancuronium, the first agent administered impacts on the duration of drug effect of the subsequently administered agent up to a point. The maintenance dose duration for pancuronium was shorter when given after rocuronium than when it was given after pancuronium. This difference continued until the third maintenance dose.

The rocuronium maintenance dose duration was prolonged when administered after pancuronium. However, the difference was only significant for the first maintenance dose. By the second rocuronium maintenance dose, the recovery duration was similar regardless of which agent was administered as the intubating dose. In this case, the influence from the first drug diminished much faster than would be predicted from their elimination half lives and likely reflects that recovery, which is due to changes in concentration at the site of effect, is due to both redistribution and elimination. Figure 2 shows the median duration of each dose for the four dosing groups.

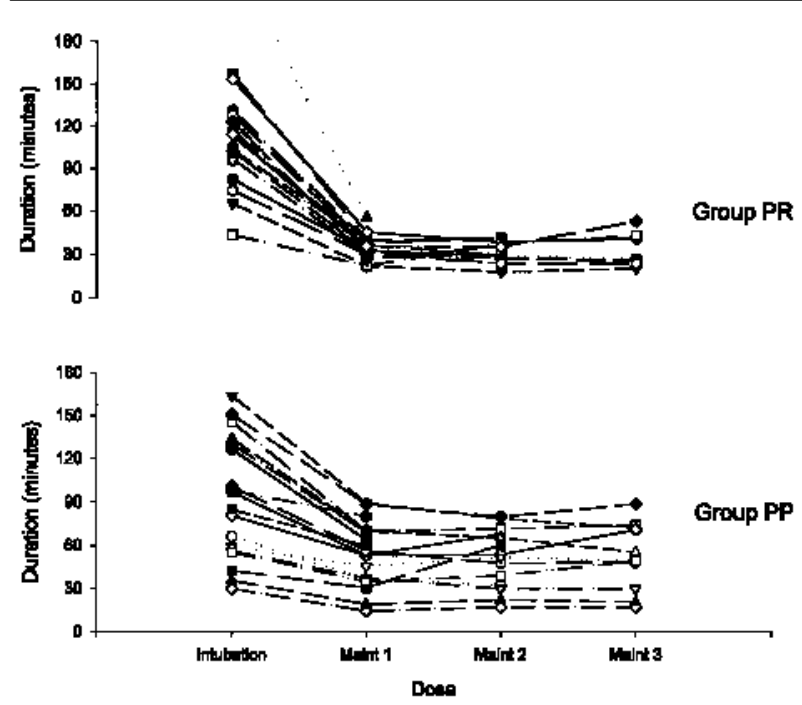

FIGURE $1 \mathrm{~B}$ Individual dose durations until recovery of Tl to $25 \%$ of baseline for each group of subjects in the study. Group PR received pancuronium for intubation and rocuronium for maintenance and Group PP received pancuronium for both intubation and maintenance.

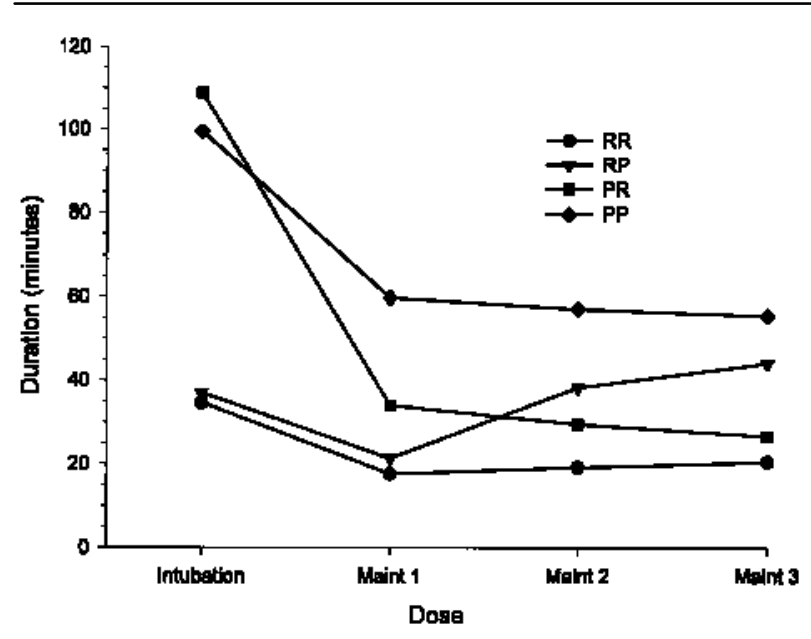

FIGURE 2 Trend in median dose duration to Tl of $25 \%$ of baseline for the four study groups. As evidence in the plot, the maintenance dose durations for Groups RP and PP converge as do groups $\mathrm{PR}$ and $\mathrm{RR}$ with each additional maintenance dose.

Apparent from this figure is the progression of the mixed dose groups towards their respective control group with each maintenance dose.

Based on the median duration values from this study, combining rocuronium with the longer acting, 
slower onset pancuronium can produce adequate relaxation profiles for surgical cases of one to two hours without prolonged recovery or duration of drug effect. Following the longer acting pancuronium with the shorter acting rocuronium extends the relative duration of action of the short acting maintenance agent briefly, that is, for one maintenance dose, until the effects of the initial dose of pancuronium recede. These results concur with other investigations which have documented the influence of the first muscle relaxant given on the duration of the effect of a second agent given in subsequent maintenance doses. ${ }^{1-4}$ While most investigations have only studied the effects of a single maintenance dose, these results, like the results of Schiere et al..$^{3}$ show that the impact on the maintenance dose duration of effect decreases with each subsequent dose.

\section{References}

1 Rashkovsky OM, Agoston S, Ket JM. Interaction between pancuronium bromide and vecuronium bromide. Br J Anaesth 1985; 57: 1063-6.

2 Erkola $O$, Rautoma $P$, Meretoja $O A$ Mivacurium when preceded by pancuronium becomes a long-acting muscle relaxant. Anesthesiology 1996; 84: 562-5.

3 Schiere S, van den Broek L, Proost JH, Molenbuur B, Wierda JMKH. Comparison of vecuronium with ORG 9487 and their interaction. Can J Anaesth 1997; 44: 1138-43.

4 Naguib M, Samarkandi AH, Bakbamees HS, Magboul $M A, E l$-Bakry AK Comparative potency of steroidal neuromuscular blocking drugs and isobolographic analysis of the interaction between rocuronium and other aminosteriods. Br J Anaesth 1995; 75: 37-42.

5 Heier T, Caldwell JE, Sessler DI, Miller RD The effect of local surface and central cooling on adductor pollicis twitch tension during nitrous oxide/isoflurane and nitrous oxide/fentanyl anesthesia in humans. Anesthesiology 1990; 72: 807-11. 